\title{
Bilateral median nerve palsy in a cyclist
}

\author{
Ian J. Braithwaite MA, FRCSEd \\ Royal Liverpool Hospital, Prescot Street, Liverpool, UK
}

Cyclists are prone to a number of sport-related musculoskeletal injuries, mainly of the lower limb. Nerve compression injuries are relatively rare, though in the hand ulnar nerve compression is well described. We describe a case of bilateral median nerve compression caused by cycling.

Keywords: Median nerve, palsy, cyclist

\section{Case report}

A 43-year-old man attended the orthopaedic clinic with a 4-month history of bilaterally altered sensation in the median nerve distribution of the hand. He was an occasional cyclist for the most part, but the day before the onset of his symptoms he had taken part in a 100-mile sponsored cycle ride. He suffered mild exhaustion and quite severe musculoskeletal aches and pains, which settled over 1-2 weeks, but in addition he noted clumsiness in both hands and pins and needles with a feeling of numbness the day after the ride which he put down to general tiredness and muscular overuse. As his general aches subsided the hand symptoms became more noticeable.

When he was seen in the clinic, 4 months after his injury, the symptoms in one hand were settling, but the other hand was as bad as ever. He complained specifically of clumsiness and weakness in the hand, and altered sensation in the index and middle fingers predominantly, but pain was not a feature. He had given up cycling, and was unable to think of any exacerbating or relieving factors.

Examination showed decreased pin-prick sensation in the median nerve distribution of the affected hand and some weakness of thumb opposition, but there was no obvious muscle wasting and provocation tests were negative.

A steroid injection into the carpal tunnel relieved the symptoms in the worst affected hand within a fortnight. The other hand continued to improve spontaneously.

Nerve conduction studies were not performed.

\section{Discussion}

Ulnar nerve palsy in a cyclist was first described by Destot in $1896^{1}$. Since then the condition has been

Address for correspondence: Mr I. J. Braithwaite, 41 York Drive, Mickle Trafford, Chester, CH2 4DT, UK

(C) 1992 Butterworth-Heinemann Ltd 0306-3674/92/010027-02 frequently documented ${ }^{2-5}$. Median nerve palsy in a cyclist has not to our knowledge been reported before.

Ulnar nerve palsy appears to be limited to professional and keen amateur cyclists. The mechanism of injury is probably direct pressure ${ }^{2}$ resulting from the way in which professional riders hold the drop handlebars (Figure 1). In this position pressure is directly over the ulnar nerve and both the motor and sensory branches may be affected ${ }^{2}$.

The occasional cyclist usually holds the handlebars on top with the wrists fully extended as shown in Figure 2. In this position pressure is directly over the median nerve. The position is more comfortable than the 'drop' position and the touring brake handles are

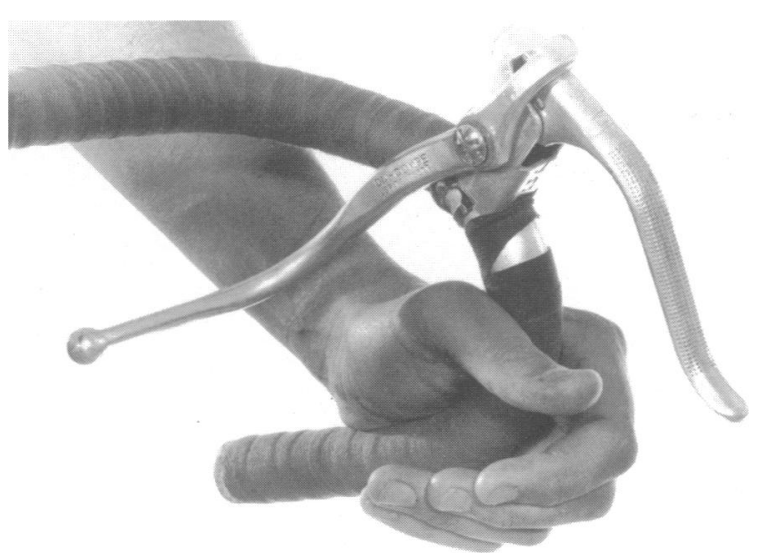

Figure 1. The professional position on the drop part of the handlebars

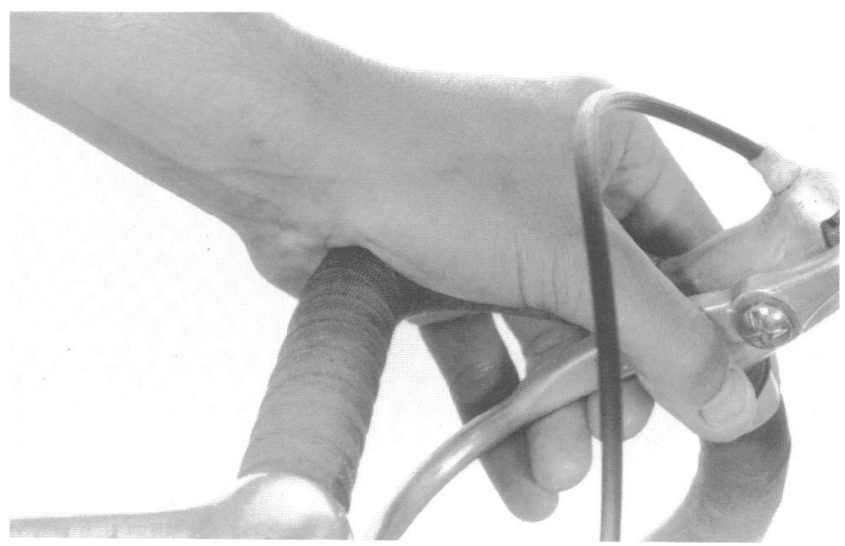

Figure 2. The more comfortable position used by occasional cyclists 
easily reached, and it was in this position on unpadded handlebars that our patient cycled for over $9 \mathrm{~h}$. Professional cyclists are not at risk because they hold the drop handle, and the average cyclist is likely to cycle only short distances varying the hand position and have padded handlebars. Only in exceptional circumstances will median nerve palsy develop, and it is likely to recover spontaneously or resolve with conservative treatment.

We recommend the use of foam padding on handlebars and frequent changes of hand position to avoid nerve compression syndromes and other hand problems associated with prolonged cycling.

\section{References}

1 Destot J. Paralysie cubitale par l'usage de la cyclette. Gaz Hôp 1896; 69: 1176-7.

2 Helal B. Hand and wrist injuries. In: Helal B, King JB, Grange WJ, eds. Sports Injuries and their Treatment. London: Chapman and Hall, 1986: 284-5.

3 Haloua JP, Collin JP, Coudeyre L. Paralysis of the ulnar nerve in cyclists. Ann Chir Main 1987; 6: 282-7.

4 Frontera WR. Cyclist's palsy: clinical and electrodiagnostic findings. Br J Sports Med 1983; 17: 91-3.

5 Maimaris C, Zadeh HG. Ulnar nerve compression in the cyclist's hand: two case reports and review of the literature. $\mathrm{Br}$ J Sports Med 1990; 24: 245-6. 